\title{
Visualizing online collaborative writing strategies in higher education group assignments
}

\author{
Marcus Sundgren \& Jimmy Jaldemark \\ Mid Sweden University, Campus Sundsvall, Sweden
}

Citation:

Sundgren, M. and Jaldemark, J. (2020), "Visualizing online collaborative writing strategies in higher education group assignments", International Journal of Information and Learning Technology, Vol. 37 No. 5, pp. 35I-373. https://doi.org/I0.II08/IJILT-02-2020-00I8

This author accepted manuscript is deposited under a Creative Commons Attribution NonCommercial 4.0 International (CC BY-NC) licence. This means that anyone may distribute, adapt, and build upon the work for non-commercial purposes, subject to full attribution. If you wish to use this manuscript for commercial purposes, please contact permissions@emerald.com 
[This page intentionally left blank] 


\title{
Visualizing online collaborative writing strategies in higher education group assignments
}

\author{
Marcus Sundgren and Jimmy Jaldemark \\ Department of Education, Mid Sweden University, Sundsvall, Sweden
}

\begin{abstract}
Purpose - Working together in groups is a common and emphasized feature in today's society, and higher educational settings often utilize group assignments to enable students to develop collaborative skills. Therefore, the purpose of this article is to describe and analyze applied strategies and the patterns that emerge during students online collaborative writing in higher education group assignments. The research questions that this article aims to answer are 1) which patterns of students online collaborative writing emerge in higher education group assignments, and 2) what strategies of online collaborative writing do higher education students apply in group assignments?
\end{abstract}

Design/methodology/approach - This study's design builds on Conversation Analysis to explore visualizations of Google Docs revision history of online collaborative writing documents. Documents from 25 student groups was the basis of the analysis. The visualizations used in this project are produced with the DocuViz Chrome extension.

Findings - The findings suggest that visualizations can provide a quick and fairly accurate estimate of collaborative strategies used when students write together online. Three patterns of document growth were identified, two of which could be directly linked to strategies for collaboration. Cramming patterns are indicative of low collaboration, and concentrating patterns with high levels of collaboration.

Practical implications - The findings provide useful insight for teachers regarding the nature of collaboration taking place during online collaborative writing tasks. By visualizing the revision history, much can be learnt about the nature of the collaboration and of the individual group member's contributions in a student group that otherwise remains largely invisible to the teacher.

Originality/value - Prior studies have combined visualizations with extensive analysis of document content. This investigation shows that an examination of the visualization of the document's revision history can be used to draw conclusions about the nature of collaboration during the online writing process.

Citation: Sundgren, M. and Jaldemark, J. (2020), "Visualizing online collaborative writing strategies in higher education group assignments", International Journal of Information and Learning Technology, Vol. 37 No. 5, pp. 35I-373. https://doi.org//0.1I08/IJILT-02-2020-0018 


\section{Introduction}

Working together in groups is nowadays a common and emphasized feature in society (e.g., European Commission, 2018; World Economic Forum, 2015). Such work embraces tasks that could be performed in various locations and at various times. They could be performed synchronously or separated in time and be located at the office, at home, or between different locations. Besides working face to face, working together could also be enabled by various digital technologies (Jaldemark et al., 2018). In recent decades, various technologies have emerged and been developed to facilitate communication between people and enable group work. For example, technologies such as desk-based video conferencing, Wikis, and other cloud-based technologies have been applied to enable group work. Besides being enabled by technology and being related to time and space, group work also relates to group sizes - such as pairs, small to large groups, or communities - and the performance of shared tasks (Dillenbourg, 1999).

Scholars discuss group work as being either a collaborative or a cooperative phenomenon (Baker, 2015; Dillenbourg, 1999; Fischer et al., 2002; Sharples, 1993; Sharples et al., 1993). In the choice between these two terms, some scholars de-emphasize the difference and treat collaboration and cooperation as synonyms. Others suggest that these terms refer to different concepts altogether, with respect to division of labor. Cooperative work includes at least sharing a common goal, toward the achievement of which each participant in the group will strive. However, cooperation also means a division of labor into sub-tasks that are split between the members of the group and assembled later in the process. As in the case of cooperation, collaborative work includes at least sharing a common goal. However, by working together collaboratively, members will pursue a shared understanding through joint work with the sub-tasks. Overall, cooperation can be seen as a more general concept and phenomenon than collaboration. Baker (2015, p. 455) claims that "collaboration is a specific form of cooperation: cooperation works on the level of tasks and actions, collaboration works on the plane of ideas, understanding, representations." Whatever term is applied, Baker's emphasis on ideas, understanding, and representations links group work to higher-order thinking, precisely such abilities and skills that students of higher education are supposed to develop.

Moreover, an emphasis on developing skills in collaboration could be linked to the ability to apply digital technologies. Such a link has emerged and is emphasized in various transnational and national policies. For example, an updated version of the European Commission (2018) key competencies for lifelong learning emphasizes the ability to work together with others and to apply digital technologies to pursue common goals. Another example from the World Economic Forum (2015) emphasizes skills in collaboration by linking them to the potential of emerging digital technologies. In such policy documents, the inclusion of these skills emerges from an analysis of needs in society. To be able to apply skills in collaboration and digital technologies in group work is therefore identified in such policies as a requirement for being able to participate in the labor market. These policies also emphasize formal education as a key to fulfilling this requirement. Therefore, higher education has an important task to nurture students' development of these skills, including developing strategies that lead to quality in pursuing common goals in collaborative settings.

Higher educational settings often utilize group assignments as a method to enable students to develop collaborative skills (e.g., Al-Samarraie and Saeed, 2018; Sun et al., 2018; Zhang et al., 2019). Collaborative writing is a form of Computer Supported Collaborative Learning (CSCL) (Liu et al., 2018), and higher education works with the inclusion of various digital technologies to nurture such collaborative skills. For example, in the study by Sun et al. (2018), discussion forum and instant messaging apps were applied. Other studies have included online collaboration hubs (Zhang et al., 2019), wiki technologies (Di Lauro and Johinke, 2017), learning management systems (Al-Samarraie and Saeed, 2018), and online writing applications such as Dropbox and Google Docs (McNely et al., 2012; Ryberg et al., 2018). 
However, the collaborative process of writing such assignments is often not in itself visible to teachers. Students utilize various applications in the process of collaboration, and teachers might not have access to those applications. Monitoring is also a time-consuming process for teachers that is compatible neither with a reasonable allocation of course resources nor with the workload of higher education teachers. However, having students work together facilitated by online writing applications such as Google Docs can give some insights regarding aspects of that process (Liu and Lan, 2015; McNely et al., 2012; Olson et al., 2017; Ryberg et al., 2018). Using the revision history to see, understand, and unravel group processes can be both difficult and time consuming. However, recent technological development enables the visualization of the version history (Olson et al., 2017; Wang et al., 2015). It is possible to unveil some parts of the collaborative writing $(\mathrm{CW})$ process and thus provide value for the teacher, both in assessment and in the planning and design of further lessons and tasks that should support the development of collaborative skills. Of particular interest in the monitoring of students' collaboration are the patterns emerging in collaboratively written assignments. These patterns could reveal successful strategies applied in group work. Such patterns and strategies could explicitly be included by teachers in discussions with students, with the intent to nurture their collaborative skills. Therefore, the purpose of this article is to describe and analyze applied strategies and the patterns that emerge during students' online collaborative writing in higher education group assignments. The research questions are as follows:

+ Which patterns of students' online collaborative writing emerge in higher education group assignments?

- What strategies of online collaborative writing do higher education students apply in group assignments?

Before discussing the methods applied to answer these research questions, a review of CW strategies and visualization of $\mathrm{CW}$ follow.

\section{Strategies for collaborative writing}

Several authors have developed nomenclature and taxonomies regarding CW strategies. Stratton (1989) described three models of labor division in workplace writing: the horizontal (each group member researches, outlines, revises, and edits his or her own section of the document), the sequential (the first group member writes up a complete version, the second revises, the third re-revises, and so on), and the stratification model (each group member takes on a different role, such as leader, data gatherer, writer, or editor). Posner and Baecker (1992) have a slightly different take on this, separating roles and writing strategies. They identified the roles of "writer," "consultant," "editor," and "reviewer" and the writing strategies "single writer" (one member writes the document based on group discussions), "scribe" (one member writes down what the group decides during a meeting), "separate writers" (each writer is responsible for a separate part), and "joint writing" (the group writes together, deciding on exact wording and sentence structure). These strategies could also be modified with "consulted" (e.g., "joint writing [consulted]") for situations where the writer(s) received outside consultations. Both Posner and Baecker (1992) and Stratton (1989) developed their models well before CW applications were readily available; thus, their models do not completely fit current online written assignment scenarios. Sharples et al. (1993) in a discussion of the impact of computer applications suggested that one way to categorize CW concerns the closeness of the collaboration. They claim that "at one extreme is the 'shared mind' ... [a]t the other is 'division of labour"' (p. 14). 
Lowry, Curtis, and Lowry (2004) set out to create a unified taxonomy of CW. It is not limited to roles and strategies, as the "process complexity of $\mathrm{CW}$ is compounded by the possibility of multiple writing strategies, writing activities, document control modes, and work modes" (p. 70). They use Posner and Baecker's four roles, with the addition of "leader" and "facilitator." The strategy categories integrate features from the work of Stratton (1989), Posner and Baecker (1992), as well as from Sharples (1993; Sharples et al., 1993). The strategies are "group single-author writing" (one member is directed to write for the whole group, cf. "scribe"), "sequential single writing" (one member writes at a time, then passes it on to the next member), "parallel writing" (work is divided into discrete units, and the group works in parallel), and "reactive writing" (group members write the document in real time, reacting and adjusting to each other's additions and changes). The parallel writing strategy can be sub-divided into "horizontal division," where each member is responsible for a particular section, or "stratified division" where group members take on different roles, such as editor, author, or reviewer. Lowry et al. also noted a "mixed strategy" for cases when two or more of the above strategies are used by a group.

Onrubia and Engel (2009) described five strategies for CW: "Parallel construction - cut and paste" (each group member contributes with a different part of the complete task), "Parallel construction - puzzle" (each member contributes a partially or entirely completed task, and the final document is constructed from parts of the individual contributions), "Sequential summative construction" (one member presents a document with a partial or complete proposal, and the rest successively add their contributions without modifying what was previously written), "Sequential integrating construction" (one member presents a document with a partial or complete proposal, and the rest of the group successively propose modifications and discuss whether they agree upon what was previously written), and "Integrating construction" (the writing is based on synchronous discussion through chat, with repeated revisions, where all members participate). These strategies developed out of a process shaped by document control and responsibility issues, stemming from the necessity to pass a single document around between group members. Some of the aspects above are thus downplayed by synchronous CW applications, where all group members theoretically at least - have equal access to and control of the document at all times.

\begin{tabular}{|c|c|c|c|}
\hline \multicolumn{2}{|c|}{ REFERENTIAL } & \multicolumn{2}{|c|}{ STRUCTURAL } \\
\hline \multicolumn{2}{|c|}{ Outcome of OCW } & Created document & Knowledge and skills \\
\hline \multicolumn{2}{|c|}{ Learning from each other } & Low & High \\
\hline \multicolumn{2}{|c|}{ Nature of OCW process } & Coordination & Collaboration \\
\hline \multicolumn{2}{|c|}{ Intensity of interaction } & Low & High \\
\hline \multicolumn{2}{|c|}{ Values and commitment } & Formal commitment & Intrinsic motivation \\
\hline \multirow{4}{*}{$\begin{array}{l}\text { Expanding } \\
\text { focus from } \\
\text { division of } \\
\text { work to } \\
\text { knowledge } \\
\text { co- } \\
\text { construction } \\
\text { \& learning }\end{array}$} & Category A & $\begin{array}{l}\text { Divide work to } \\
\text { complete the task }\end{array}$ & \\
\hline & Category B & \multicolumn{2}{|c|}{$\begin{array}{l}\text { Combine expertises to produce } \\
\text { a good end product }\end{array}$} \\
\hline & Category C & \multicolumn{2}{|c|}{$\begin{array}{l}\text { Fuse ideas and insights to enable deeper } \\
\text { understanding }\end{array}$} \\
\hline & Category D & \multicolumn{2}{|c|}{$\begin{array}{l}\text { Develop new skills and attitudes for collaborative } \\
\text { work }\end{array}$} \\
\hline
\end{tabular}

Figure I. Hierarchical relationship among conceptions of OCW (reprinted with permission from Limbu and Markauskaite, 2015, p. 399) 
Limbu and Markauskaite (2015) studied students' conceptions of online collaborative writing (OCW), and they brought together aspects from the above authors and described a model adapted to the specific conditions of OCW. Their model positions categories of how students perceive OCW on a continuum spanning from a simple division of work to a process of knowledge co-construction and learning (Figure 1). These categories can be seen as different strategies for CW.

Limbu and Markauskaite point out that students could benefit from becoming aware of their stances toward knowledge and learning, as those stances could be more or less productive. It is in part the teacher's responsibility to remedy this by clearly conveying the objectives of the task.

\section{Visualizing collaborative writing}

There is a history of solutions to provide a view of how a collaboratively authored document emerges. An early example of visualization of CW is the work of Fischer et al. (2002). Their study showed that visualization technology could enable the fostering of collaborative knowledge construction. Later, Wang et al. (2015) provided an overview of applications for visualizing CW. They found that many of those applications were not constructed for simultaneous online writing; thus, they created an extension to Google Chrome that produces a visualization of the Google Docs version history. They suggest that this type of visualization can be beneficial to both groups and teachers because it allows information to be perceived in context and according to their needs, which is more powerful than text-based commentary. The importance of group awareness for student engagement is also demonstrated by a recent CSCL study that examined OCW tasks performed with a tool that visualized collaborative indicators (Liu et al,, 2018). Olson et al. (2017) used DocuViz in their analysis of advanced undergraduates' CW and found that student groups write both synchronously and asynchronously, fluidly take on different writing and editing roles, and employ a variety of CW strategies. They conducted a thorough analysis of the quality of the final texts, and found that longer documents and documents that included balanced participation or exhibited leadership were of higher quality. 


\section{Method}

The analysis in this study built on ideas from conversation analysis (CA) and linked it to online communication in terms of online writing. In such analysis, unfolding rules and structures of human interplay in different cultures and settings are emphasised. Earlier studies applying CA in online settings have for example analyzed face-to-face and online communication; trouble-dealing of participants; asynchronous social actions; and the maintenance of coherence in terms of for example turn-taking (e.g., Paulus et al., 2016; Tan and Tan, 2006). The study drew on CA in terms of analyzing turn-taking in the communicative interplay of participating students' OCW. These turn-takings were the links in the chain of actions students performed together while writing and editing the document. Further, from a CA perspective, the study emphasized turn-taking in terms of writing and editing as a phenomenon built on conversational rules and structures (Paulus et al., 2016; Tan and Tan, 2006), which became visible in terms of the patterns that emerged while students collaboratively wrote and edited an online written group assignment. To reveal the strategies applied by groups in the OCW, the study sought to uncover patterns that emerged in collaboration between students.

The basis for the analysis was the graphs produced by the Google Chrome extension DocuViz for Google Docs created by Wang et al. (2015). It is a general-purpose application for visualizing the revision history of Google Docs, and could in part be considered as an application of learning analytics (Southavilay et al., 2013). It generates a graphical overview of the entire revision history, showing when the students write and what part of the document is authored by whom.

The vertical axis in the generated graph (see Figure 2) represents the text content, with the first character in the document at the top and the last character at the bottom. The horizontal axis is a timeline, starting with the document creation at the left. Each colored column is a representation of the actual document in miniature, from top to bottom, with the separate colors identifying different students' contributed text at a point in time. Lines connect text segments between editing sessions, making it possible

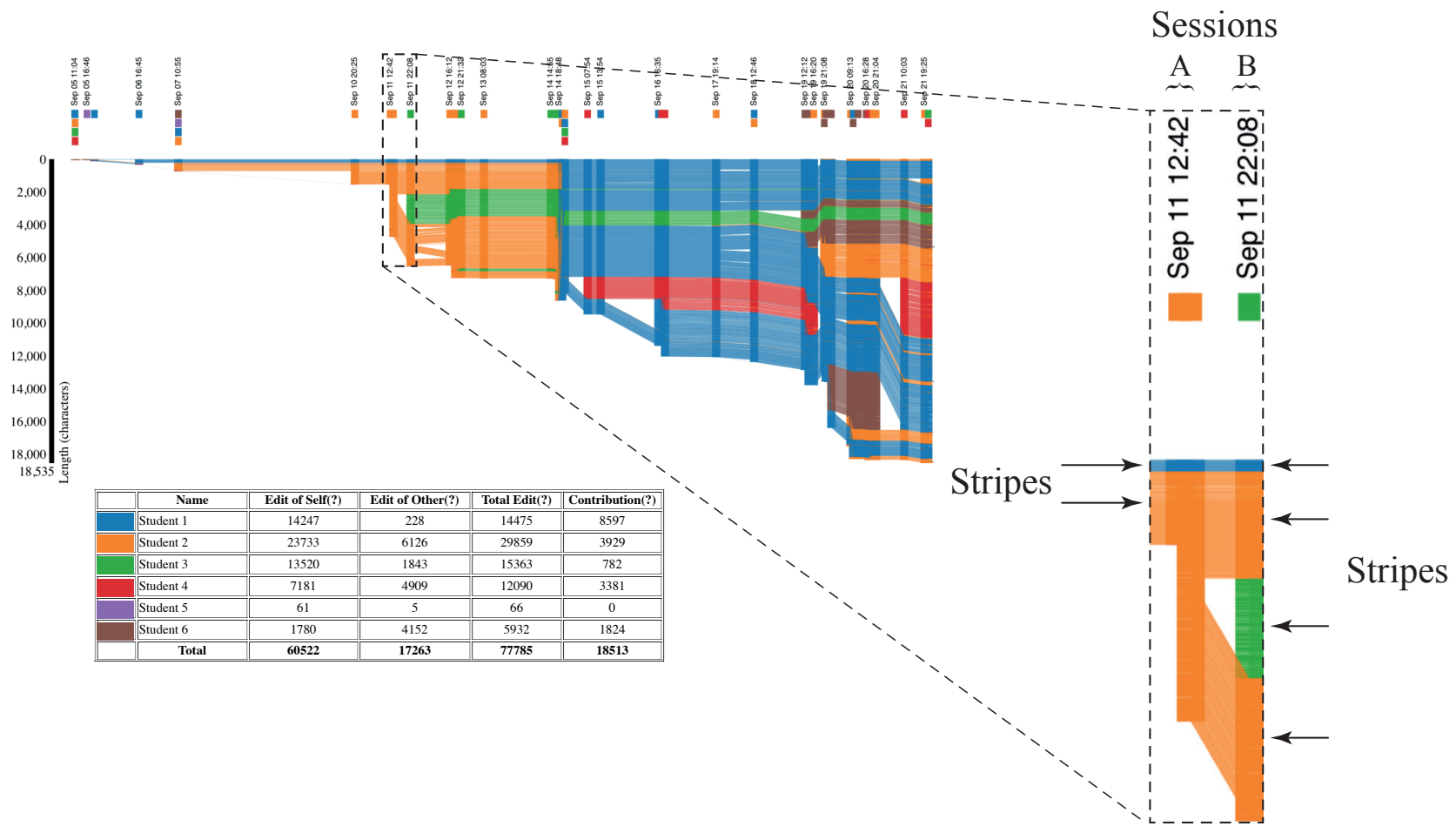

Figure 2. Example of a DocuViz output on top with its statistics table on the bottom left. To the right, an excerpt that illustrates a session (column) and a stripe (horizontal single-color field). 
to follow where a particular segment of text is located in each revision of the document. A couple of terms needed for the discussion of these graphs are defined next.

A session is defined as a single vertical column in the DocuViz graph, marked by a date printed above the horizontal axis (A and B in Figure 2). This is what constitutes a single continuous session of work. A session can be either joint or solo. In a joint session, several colored squares denoting the students participating are stacked above the column; a single colored square denotes a solo session (as seen in Figure 2).

A stripe is defined as a horizontal solid color field, or row (marked by arrows in Figure 2), representing a contiguous segment of text (one character or more) that is an edit of a single student. A block of text originally written by student $\mathrm{X}$ would constitute a single stripe, for example the orange part of column $\mathrm{A}$ in Figure 2. If student $X$ later extends that text block it would remain one stripe, but if student $Y$ makes an edit within that sentence, such as the green part in session B, the original stripe becomes split into two (session B in Figure 2), creating a representation of turn-taking.

The DocuViz extension also produces various statistics, such as the number of characters edited (by both self and others) and the amount of contributed characters per student remaining in the final document. Three indicators were calculated (see Table 2) from those statistics. The first indicator, the Timespan, was obtained by calculating the number of days from document creation to document completion. This indicator can be used to illustrate time spent on the assignment. The second indicator, called Turntaking, was obtained by counting the number of colored stripes in the last session and is an important measure for the CA. This gives an indication of the amount of collaboration taking place. The third and last indicator is Concentration, which was obtained by dividing the maximum document length by the submitted document length. If this variable is close to 1 principally everything added to the document was retained in the final version. The larger this variable is, the more editing to process and refine the initial text contributions is required, and more negotiation of the content is likely needed.

\section{Sample}

The dataset consists of 25 Google Docs documents with revision history, collected from two consecutive years of students taking introductory courses in two teacher education programs (preschool class trough grade three, and grade four through grade six), and the assignment took place during the first three weeks of their first semester. The reason for using this specific assignment was that study groups were new and not yet set in their habits, and therefore has a better chance of displaying variation in collaborative patterns and strategies than assignments later in their education. Students were divided into study groups by the teachers and tasked with using Google Docs to do a group assignment writing a text on educational history. Because these programs are given in a blended format with 3-4 face-to-face campus meetings

Table I. Overview of sampled groups and students. The teacher education program orientations are preschool class through grade 3 (Pre-3), and grade 4 through grade 6 (4-6).

\begin{tabular}{lllll}
\hline Semester & Program & Groups (Total) & $\begin{array}{l}\text { Groups with } \\
\text { visualizations }\end{array}$ & $\begin{array}{l}\text { Students with } \\
\text { visualizations }\end{array}$ \\
\hline 2016 & Pre-3 & 9 & 6 & 34 \\
2016 & $4-6$ & 6 & 4 & 29 \\
2017 & Pre-3 & 10 & 9 & 51 \\
2017 & $4-6$ & 6 & 6 & 32 \\
\hline & & 31 & 25 & 146
\end{tabular}


per semester combined with distance studies, students live in many different areas of Sweden. Therefore, group composition was primarily based on geographic location to make face-to-face meetings possible. In total, 31 groups were formed, with group sizes ranging from 3 to 8 students $(M=5.7, S D=1.48)$. Four documents could not be processed by the DocuViz extension. Another two groups are excluded from the analysis, one because a group failed to submit a document on time, and one because the document creator deleted the document prior to this analysis. This left 25 group documents for analysis (Table 1). In total, 146 students participated in these 25 groups $(M=5.8, S D=1.49)$.

All visualizations were printed, visually examined side by side by the authors, and grouped based on distinguishing visual features. This grouping allowed three distinct categories to be formed.

\section{Procedure}

An introductory lecture was held by the first author on campus at the beginning of the course, where an assignment was presented and an introduction to Google Docs was provided. The purpose of the assignment was for students to demonstrate knowledge of different perspectives on the history of public education in Sweden, but also to show their ability to use CW applications, specifically Google Docs. The assignment was to write an argumentative text to answer the question: "What evidence have we in the study group found for the school seen as a function of various societal factors, or as an instrument for policy makers to change society/societal development?" (from teacher PowerPoint presentation, translation by the authors). The only instructions regarding the format were to: 1 ) present two examples for each of the two different ways of interpreting the history of education, 2) to present their argumentation clearly, 3) to use correct reference management, and that 4) all group members had to participate visibly, e.g. their contributions needed to be visible in the revision history. No templates or examples were given by the teacher.

Students were instructed to create a document specifically for this assignment and to make sure that all group members had access to it before leaving campus. It was pointed out that all students needed to be individually logged in, on their own accounts, when editing for the revision history to correctly report their participation. However, a student email to the first author revealed that at least one group had a single student acting as a scribe during some face-to-face meetings, performing all the edits the group decided on, leading to the revision history not reflecting all individual students' contributions. Approximately three weeks were allotted for assignment completion. The finalized assignment was handed in by giving the first author editing privileges to the documents. The second author did not participate as a teacher in the course.

During the introductory lecture, students were informed that their documents were subject to research in an anonymized form and that they were allowed to decline participation. All students verbally confirmed their participation in class. As peer pressure might affect their answers, a second opportunity to decline participation was offered. Students could signal their wish to opt out by not participating in a survey via a classroom clicker, as this could be done without peers noticing. A third opportunity to decline participation was to retract editor privileges - or to delete their document - after the assignment had been marked and reported. One group selected to delete their document. The DataViz visualizations were not created until at least a year after the last group handed in their assignments. 


\section{Results}

The presentation of the results is organized in three parts. First, an overview of the main results is presented. Thereafter, two sections follow, which correspond to the research questions, one exploring patterns of document growth and the other strategies for OCW.

For all documents, basic descriptive measures were collected. They are presented together with the calculated indicators described above and the visual categorizations in Table 2. The length of the submitted documents varies from 4707 to 21509 characters, with an average of 10769 (SD = 4 571). This equals approximately 1.5 to $9 \mathrm{~A} 4$ pages in length $(\mathrm{M}=3, \mathrm{SD}=1)$.

Table 2. Descriptive measures and categories for all group documents.

\begin{tabular}{|c|c|c|c|c|c|c|c|c|}
\hline Group ID & Group Size & $\begin{array}{l}\text { Length of } \\
\text { Submitted } \\
\text { Document } \\
\text { (Chars) }\end{array}$ & $\begin{array}{l}\text { Concentra- } \\
\text { tion }\end{array}$ & $\begin{array}{l}\text { Time Span } \\
\text { (Days) }\end{array}$ & $\begin{array}{l}\text { Total edits/ } \\
\text { Document } \\
\text { length }\end{array}$ & Sessions & $\begin{array}{l}\text { Turn- } \\
\text { taking }\end{array}$ & Category \\
\hline 4 & 5 & 6933 & 1.000 & 1 & 1.03 & 3 & 20 & Cramming \\
\hline 20 & 3 & 5821 & 1.009 & 3 & 1.99 & 4 & 56 & Cramming \\
\hline 29 & 5 & 11398 & 1.000 & 5 & 1.49 & 8 & 46 & Cramming \\
\hline 30 & 6 & 4701 & 1.000 & 5 & 1.19 & 7 & 32 & Cramming \\
\hline 18 & 5 & 6887 & 1.046 & 6 & 11.51 & 9 & 141 & Hybrid \\
\hline 11 & 5 & 21509 & 1.000 & 8 & 4.03 & 19 & 113 & Expanding \\
\hline 27 & 3 & 8126 & 1.025 & 8 & 1.95 & 11 & 19 & Expanding \\
\hline 15 & 8 & 7083 & 1.000 & 9 & 3.10 & 22 & 63 & Expanding \\
\hline 23 & 6 & 9869 & 1.000 & 9 & 5.90 & 22 & 270 & Expanding \\
\hline 28 & 7 & 16723 & 1.000 & 9 & 2.03 & 17 & 296 & Expanding \\
\hline 31 & 6 & 4795 & 1.000 & 14 & 2.08 & 14 & 47 & Expanding \\
\hline 5 & 5 & 17658 & 1.000 & 15 & 1.31 & 17 & 30 & Expanding \\
\hline 26 & 6 & 18513 & 1.001 & 15 & 4.20 & 25 & 141 & Expanding \\
\hline 3 & 4 & 7018 & 1.122 & 6 & 3.51 & 14 & 53 & Hybrid \\
\hline 1 & 7 & 13189 & 1.087 & 9 & 4.61 & 16 & 306 & Concentrating \\
\hline 19 & 5 & 10166 & 2.672 & 9 & 11.02 & 24 & 112 & Concentrating \\
\hline 14 & 8 & 11209 & 1.578 & 10 & 8.38 & 24 & 142 & Concentrating \\
\hline 13 & 8 & 8181 & 1.312 & 11 & 4.02 & 18 & 112 & Concentrating \\
\hline 25 & 4 & 9129 & 1.162 & 13 & 6.30 & 17 & 200 & Concentrating \\
\hline 17 & 6 & 13354 & 1.061 & 14 & 6.75 & 15 & 300 & Concentrating \\
\hline 2 & 8 & 16770 & 1.218 & 15 & 9.59 & 24 & 257 & Concentrating \\
\hline 6 & 5 & 6971 & 1.240 & 15 & 8.22 & 20 & 156 & Concentrating \\
\hline 24 & 6 & 11356 & 1.202 & 15 & 7.05 & 25 & 209 & Concentrating \\
\hline 21 & 8 & 8942 & 1.236 & 17 & 7.19 & 26 & 145 & Concentrating \\
\hline 22 & 7 & 12935 & 1.362 & 17 & 9.73 & 36 & 363 & Concentrating \\
\hline
\end{tabular}




\section{Patterns of document growth}

From a visual examination of the DocuViz visualizations, three patterns of document growth emerged that exemplify different approaches to assignment completion. These patterns have been named Cramming, Expanding, and Concentrating. Strategies of student collaboration were not considered in this categorization. Each pattern is presented in more detail below.

In the Cramming pattern, tasks appear to be divided up between the students at the outset, and then students work separately, likely using an offline word processor. During a relatively short period (1 to 5 days), the students assemble their document from the individual pieces by pasting text into the Google Docs document, possibly during a joint session. The most extreme example of this strategy is shown in Figure 3. This document is created at 9:30 in the morning, and a few lines of text are added. At 2:30 in the afternoon, chunks of pre-written text are pasted in during a joint session, and the assignment is submitted. The only apparent negotiation of content is regarding in what order to put the pieces. None or very few examples of students editing other group members' contributions can be discerned.

Svensk utbildningshistoria grp \#

Student 1, Student 2, Student 3, Student 4, Student 5

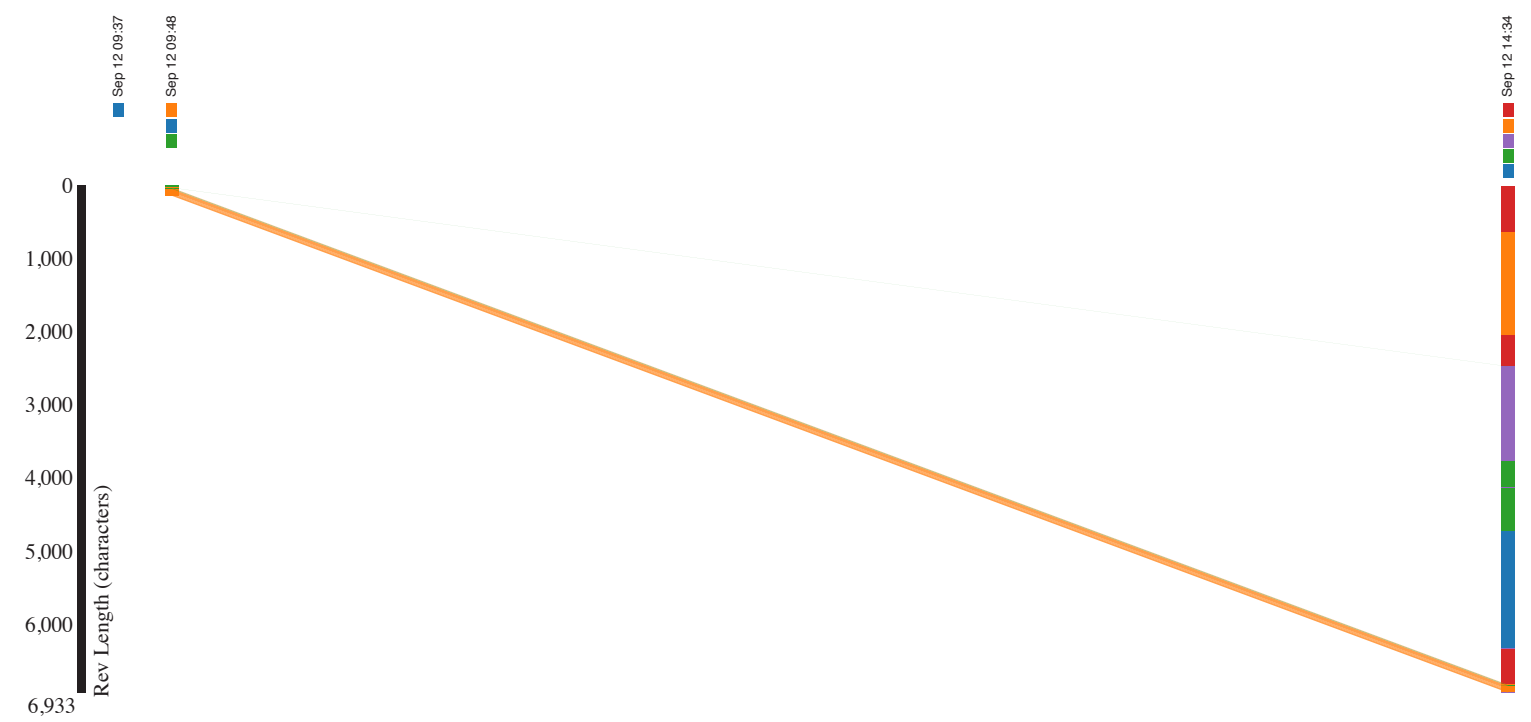

Figure 3. Example I of the Cramming pattern of document growth. Note that all sessions are on the same date, just a few hours apart.

A less extreme example can be seen in Figure 4, where students assemble their individually constructed pieces during a joint session. Individual students then touch up and piece out omissions over a few days before a final joint session where they agree to submit it. There are relatively few examples of students editing contributions of other group members.

In the Expansion pattern, there is a fairly continuous build-up of text in the document, with material added evenly along the way, from the time the assignment is introduced until the assignment is completed (Figure 5). All contributions typically add to the document length, and most students only edit their own contributions.

In the Concentration pattern, students start to add material to the document fairly well in advance of the deadline. It might start with a substantial chunk from the outset (Figure 7), or content might build up gradually (Figure 6). What makes this pattern significantly different from the Expansion pattern is a distinct reduction of the content length (more than 5 percent) along the way. Students have gathered more 
material than deemed necessary, and parts of that initial content are removed during one or more editing sessions, resulting in the content becoming more concentrated.

Grupp \# skolväsendets historia

Student 1, Student 2, Student 3, Student 4, Student 5
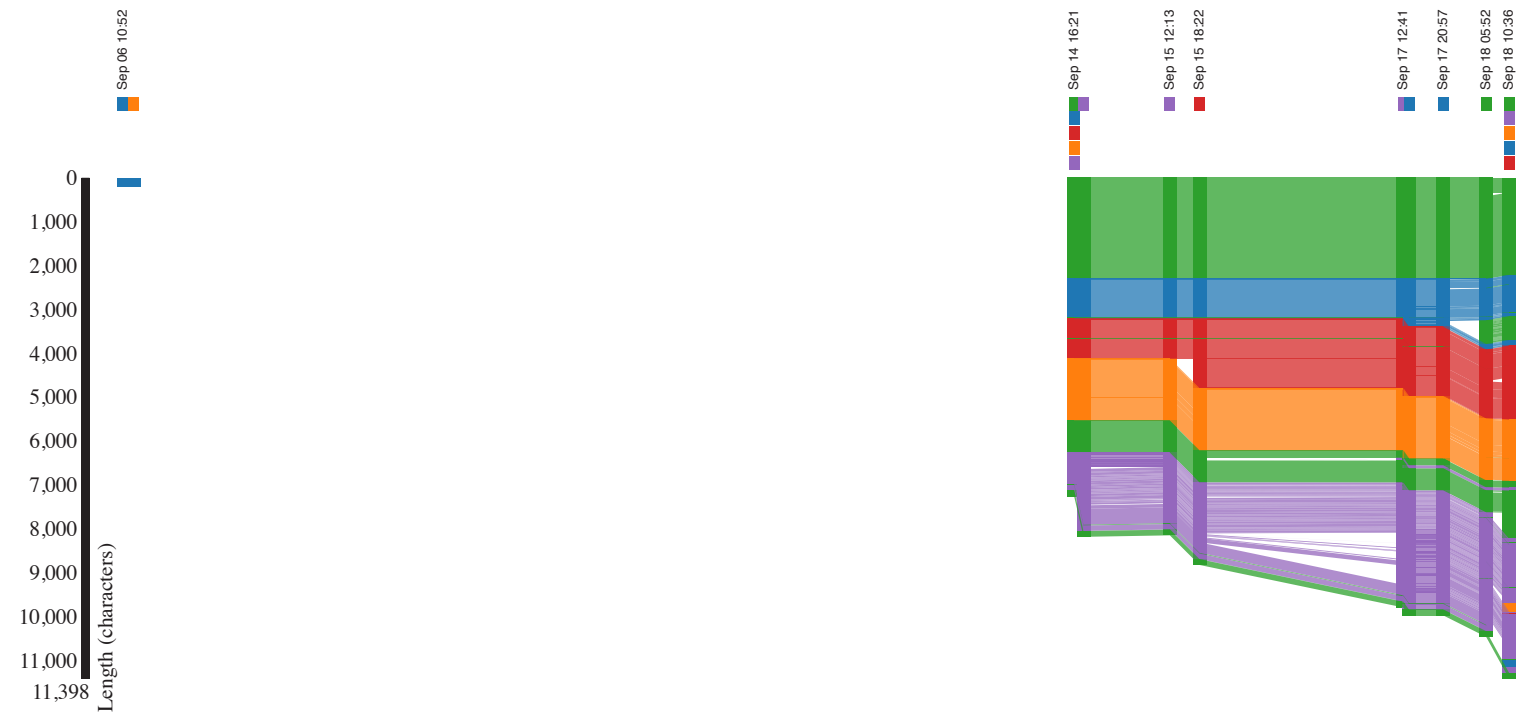

Figure 4. Example 2 of the Cramming pattern of document growth, which is more extended in time.

Grupp \# Grundskolans historia

Student 1 , Student 2, Student 3, Student 4, Student 5 (excluded), Student 6

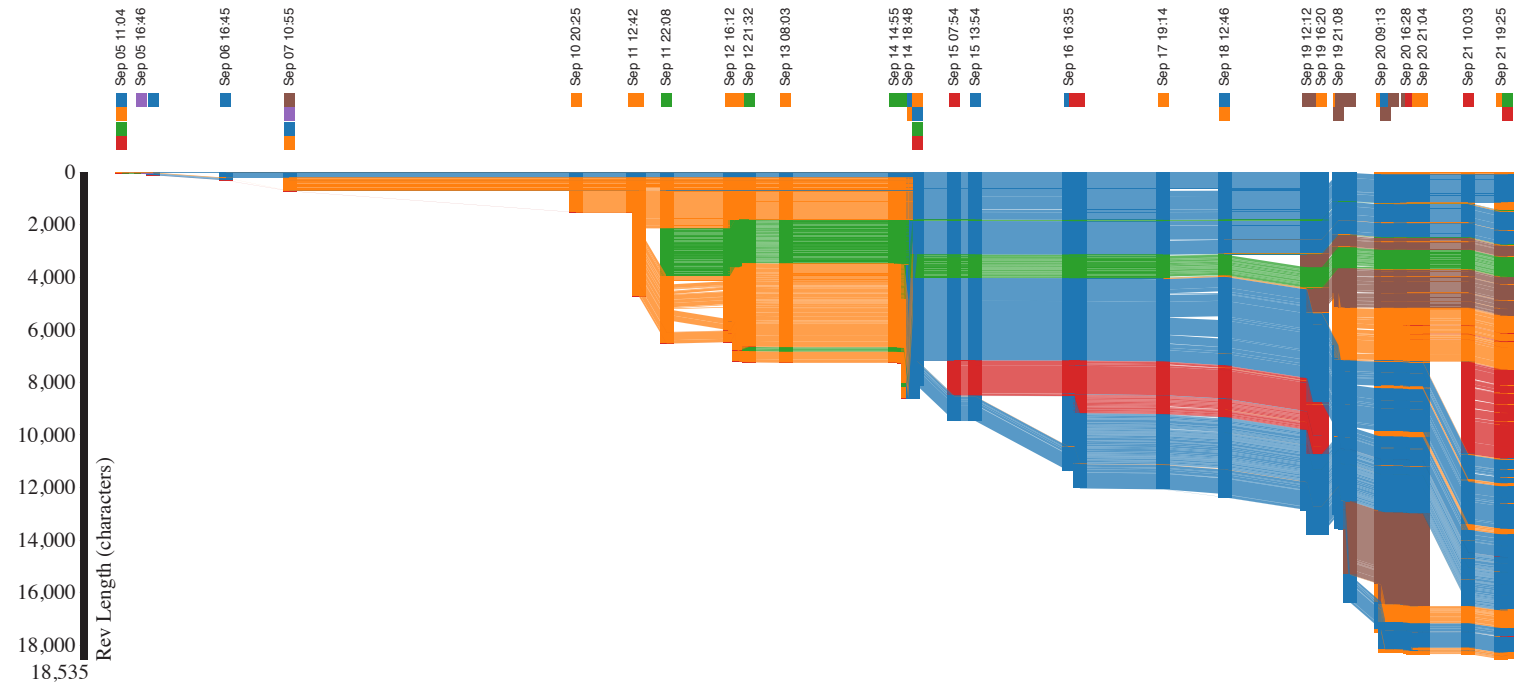

Figure 5. Example of the Expansion pattern of document growth. Material is added to the document in a continuous fashion.

Finally, two documents (18 and 03) did not fit any of the above "ideal types", as they showed signs of a blend of patterns. Document 18 appears to be a mix of cramming and expanding, and document 03 seems to be a mix of expanding and concentrating patterns. These documents were categorized as Hybrid.

To explore the boundaries of the visual categories, the indicators Timespan and Concentration were investigated. In Figure 8, all documents are plotted according to those indicators. A zone from the fifth to the eighth day separates the cramming category from the expanding and concentrating categories on the Timespan axis. All the documents in the cramming category is thus completed within approximately one 
quarter of the allotted time (26.3\%). The expanding and concentrating documents have all been processed during 8 to 17 days (42.7-89.5\% of allotted time).

On the concentration axis the bottom two categories, cramming and expanding, are separated from the concentrating category by a zone from 1.025 to 1.061 . Besides document 27 (1.025), all other documents are 1.001 or lower. The discrepant value of document 27 can be attributed to what seems to be an editing mistake late in the process, where half a page of text was pasted in the wrong place, then pasted

Grupp \# Grundskolans historia

Student 1, Student 2, Student 3, Student 4, Student 5
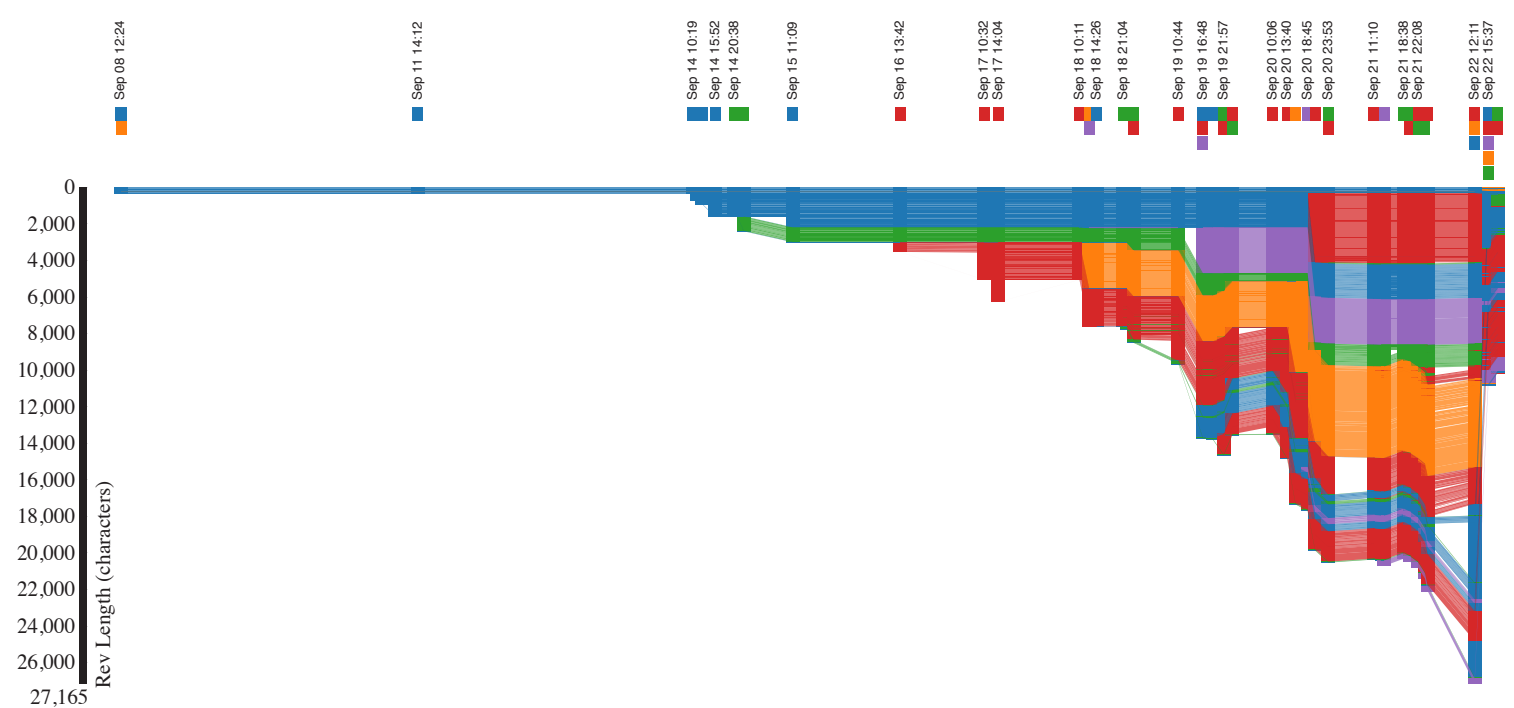

Figure 6. Example I of the Concentration pattern. In this example, a majority of content is removed during a joint session shortly before the deadline.

Gruppuppgift grundskolans historia grp \#

Student 1, Student 2. Student 3, Student 4, Student 5, Student 6, Student 7. Student 8
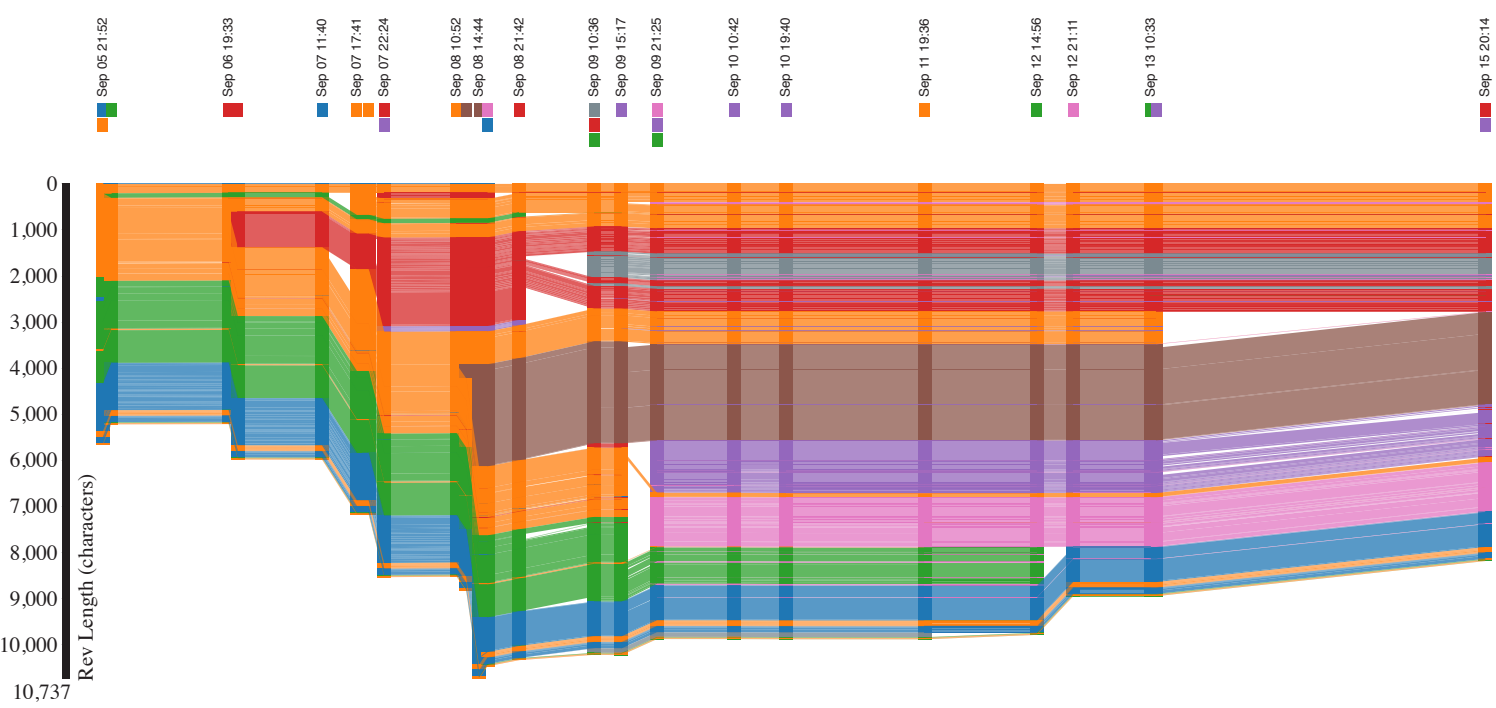

Figure 7. Example 2 of the Concentration pattern. In this example, most material is added early on, and most of the following work consists of edits of the text. The reduction is less dramatic than in Example I.

into the intended location, and finally the unintended paste was removed. This led to a maximum document length higher than the final document length by $2.5 \%$, but not due to engaged text processing. The concentrating documents start at 1.061 and extends to 2.672 , with half of the documents ranging from $20.1 \%$ to $36.4 \%$ of text reduction. 


\section{Strategies for online collaborative writing}

The visual representations of the version history can to some degree reveal the level of OCW in the making of the text. The turn-taking concept from CA is reflected in the number of stripes in the visualizations, which in turn is indicative of the level of OCW. On one extreme of the continuum is a completely cooperative strategy, and on the other extreme is a completely collaborative strategy - or shared mind (Sharples et al., 1993).

In Figure 9 an example of a strategy on the cooperative end of the continuum can be seen, where each student stays within his or her own block of content, not touching the other students' contributions, either due to fear of negative relational consequences (Birnholtz et al., 2013) or because of a division of labor. This low level of turn-taking manifests as a few large solid-color stripes in the visualizations.

On the other end of this continuum, students use a more collaborative strategy (Figure 10), where all or most - students participate in the creation of all parts of the text. Participation can be anything from the contribution of new content to corrections of typos or spelling mistakes, but there appears to be no hesitation about editing other students' contributions. This higher level of turn-taking shows up in the visualizations as many thin lines of interchanging colors.

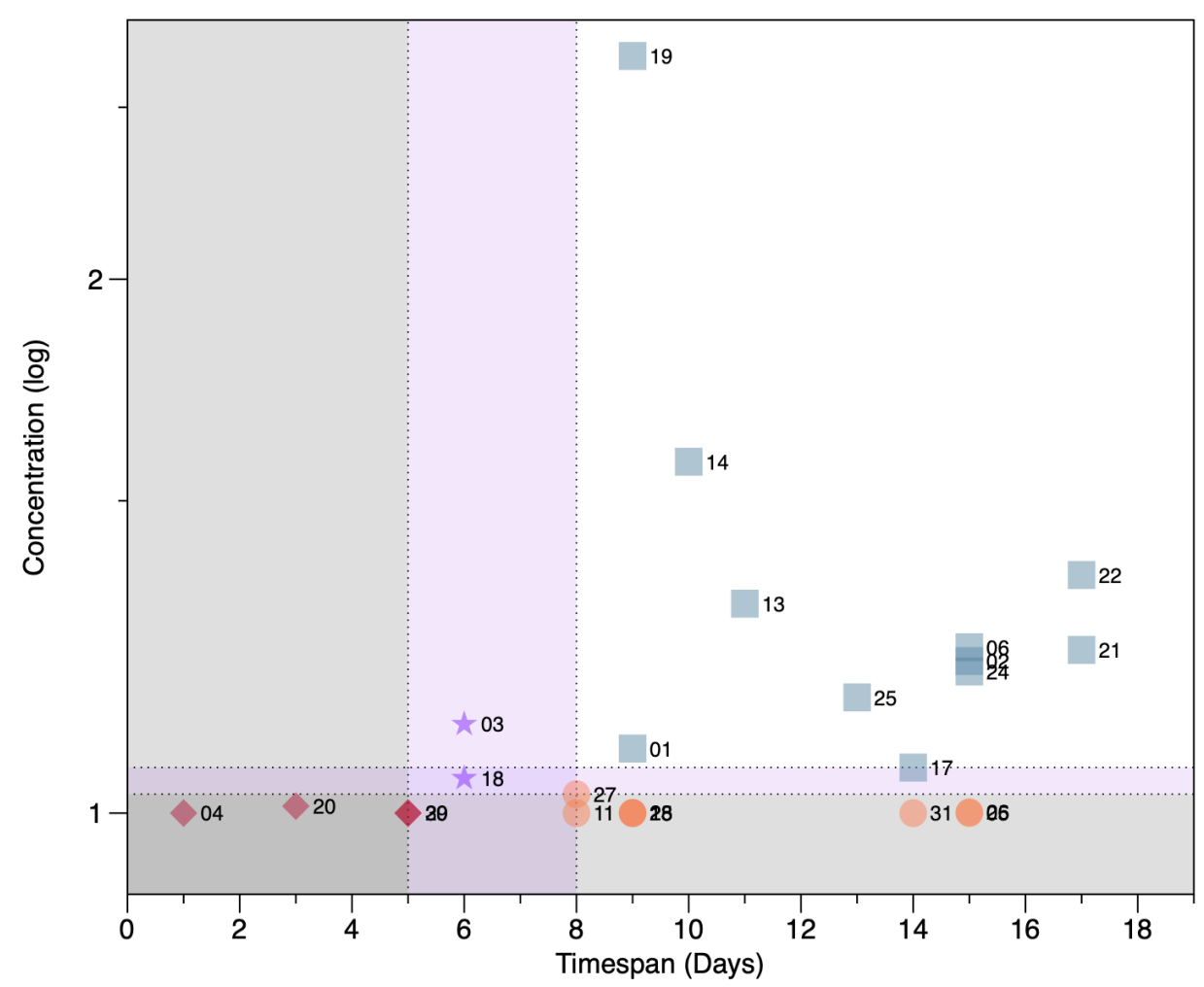

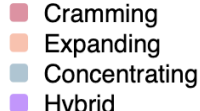

Hybrid

Figure 8. Documents plotted according to number of days editing (Timespan) and total edits per submitted document length (Concentration).

Between these extremes, many intermediate degrees of collaboration can be observed. The number of stripes in the DataViz visualizations indicates the amount of turn-taking occurring during the OCW process, giving a visual estimate of how collaboratively oriented the strategy was.

In Figure 11, turn-taking represented by number of stripes are plotted against timespan. Documents in the upper right corner would represent the highest level of interplay with both the document and with other students. In the lower-left corner documents with the least amount of interplay between students 
and with the document can be found. Nearly the same pattern as in Figure 8 can be seen, but one interesting difference is that the expanding category is spread out along the turn-taking axis. This indicates that two different strategies for collaboration have been used. A close examination of the visualizations confirms this, where documents 05, 15, 27 and 31 have mostly thick solid color stripes (much like in the cramming category), whilst documents 11,23, 26 and 28 have thin intermixed color stripes indicating collaboration on all parts of the texts (much like the concentrating category).
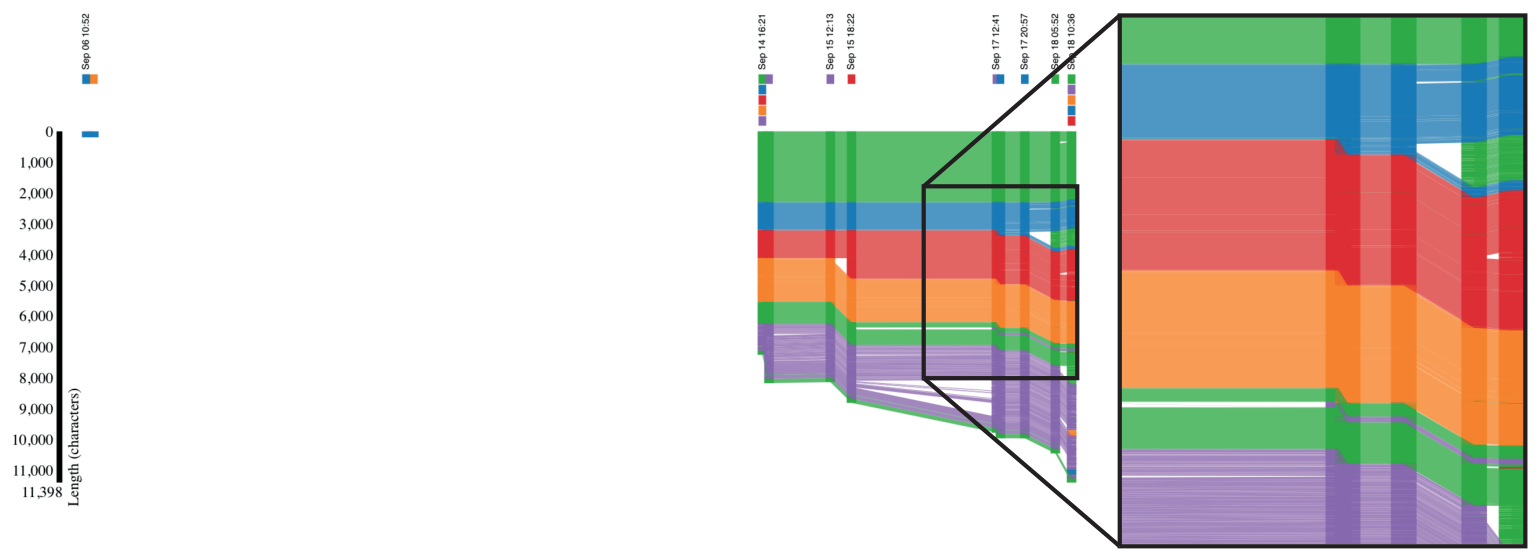

Figure 9. Example of a cooperative strategy, where students almost exclusively stay within their own blocks of content.

Looking at the two categories that are differentiated with regard to OCW strategy, it can be noted that the highest value in the cramming category (56 for document 20 ) is exactly half the value of the lowest value in the concentrating category (112 for documents 13 and 19). This signals a rather substantial difference in interplay in the writing processes between these two categories.

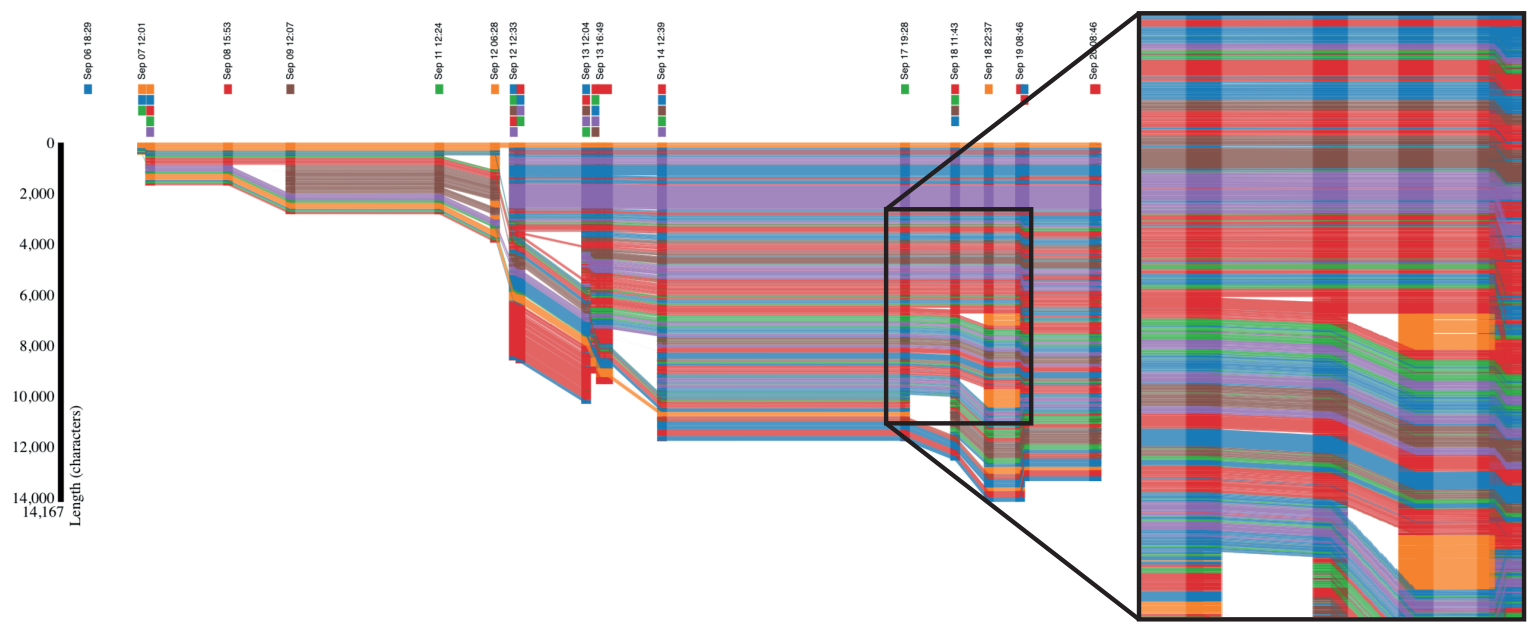

Figure 10. Example of a collaborative strategy where all students contribute to the editing of all parts of the content. 


\section{Discussion}

The purpose of this study was to describe and analyze applied strategies and the patterns that emerged during students' OCW in higher education group assignments. Three categories of document growth emerged as possible to distinguish visually: cramming, expanding, and concentrating. Two of these patterns are also likely to occur together with specific strategic categories.

The cramming pattern is quite easy to distinguish visually, and also easy to link to the class of strategies exemplified by the "parallel construction - cut and paste" strategy described by Onrubia and Engel (2009) and the "Category A" described by Limbu and Markauskaite (2015).

The concentrating pattern is also rather easy to distinguish, and that pattern seems most likely to occur in tandem with a collaborative strategy. A look at the amount of turn-taking can confirm that. This is indicative of Onrubia and Engel's (2009) integrative construction strategy or Limbu and Markauskaite's

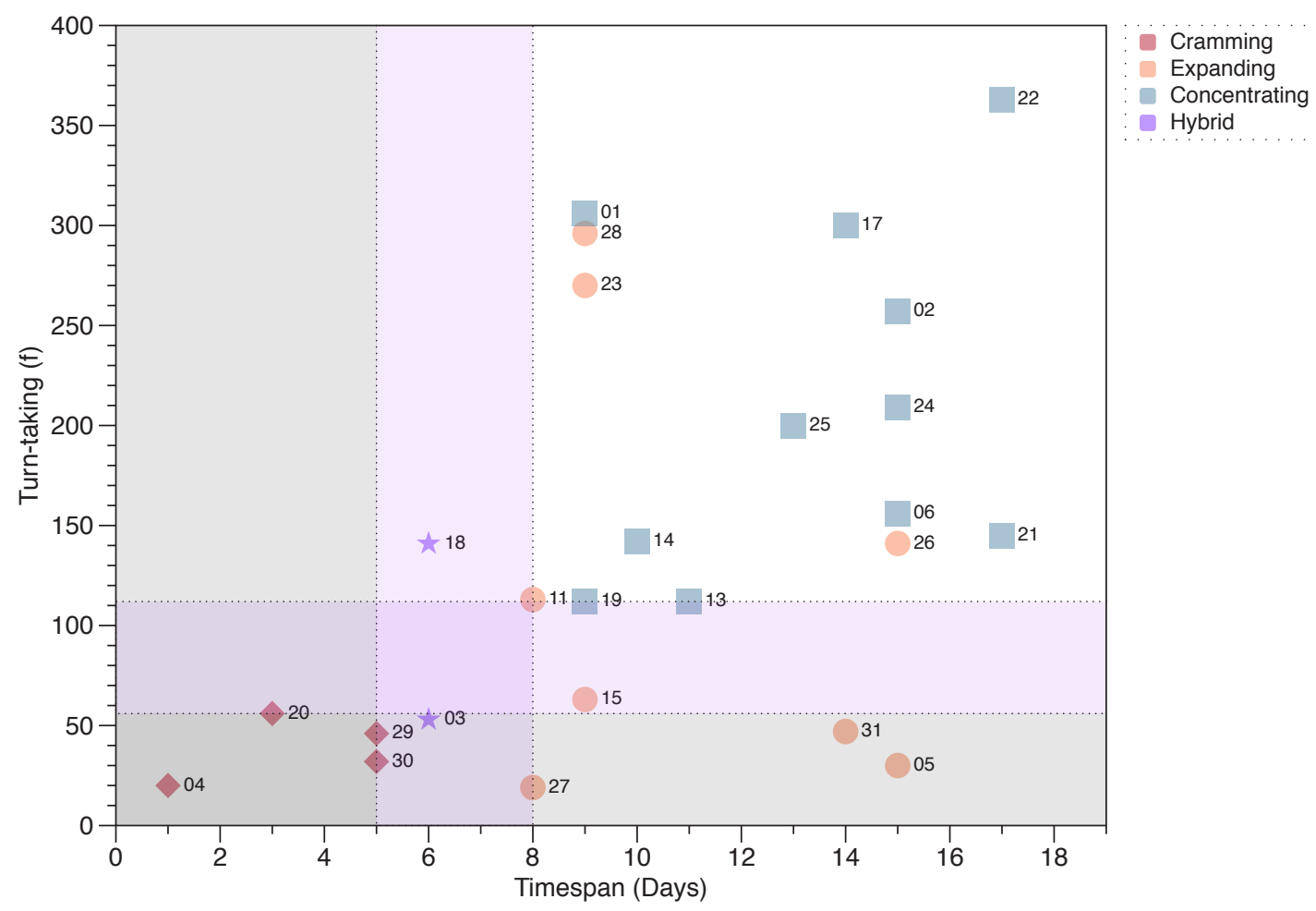

Figure II. Number of days spent editing the document (Timespan) plotted against number of stripes (Turntaking).

(2015) categories C and D.

The expanding pattern does not in itself signal more than time-on-task, as it is not as unambiguously linked to a specific strategy. It is, however, easy to visually determine whether the strategy was collaborative or cooperative by looking at the turn-taking strategy that can be deduced from the amount and mix of stripes. The more cooperatively oriented documents might be the result of undue territorial considerations, e.g. respect for other writers' demarcations and personal space (Larsen-Ledet and Korsgaard, 2019). It is not unusual for student groups to use a mixture of two or more strategies (c.f. Lowry et al., 2004) which might render the visualizations less distinct (e.g., documents 03 and 18).

To conclude, the shape of the graph (the pattern of document growth), and the stripiness (the amount of turn-taking) will indicate the nature of the strategies for $\mathrm{CW}$ taking place during the document writing process. The cramming category would likely be the result of division of work, with low levels of learning 
from each other, low intensity of interaction and be driven by formal commitment. The concentrating category would on the other hand likely result from a collaborating strategy, with a high intensity of interaction, possibly high levels of learning from each other and be driven more by intrinsic motivation (Figure 1). The expanding category can be examined with regard to the amount of turn-taking, and if low levels are found, it might be fruitful to address undue territoriality, for instance by encouraging trust within the group.

It is quite conceivable that a lot of text processing can take place without engaging with other students' contributions. This would not be reflected in the number of stripes as there is no turn-taking involved. It is also possible that a group can work intensely during a shorter period, which would not be reflected in the timespan indicator. Furthermore, any activity taking place outside editing of the Google Docs document itself will not be reflected, such as communication face to face or via other social media. Therefore, it would not be recommended to rely exclusively on the visualizations when drawing conclusions about collaborative strategies. Despite these shortcomings, data suggests that these visualizations still can provide practical utility in exposing how OCW processes takes place, which can be of value for teaching in formal higher educational settings.

\section{Implications for practice}

A seemingly superficial visualization can consequently provide a surprisingly rich overview of the collaborative patterns and strategies employed in a higher education OCW assignment. An educational implication is that the application of OCW in teaching practices can, in turn, be a time-efficient and simple way for teachers to assess qualitative aspects of the collaborative process that otherwise would be concealed and inaccessible. Implementing visualization could assist in developing teaching practices of OCW that focuses on strategies and the division of labor applied in group work. In such practices, visualization could enable the identification of groups with low levels of a shared mind in Sharple's terms (1993; Sharples et al, 1993). The current study suggest that patterns of document growth and turn-taking can reveal such low levels of a shared mind. By identifying groups with a cramming pattern, remedial or compensatory action could be applied and implemented. Applying such actions in teaching practices could nurture development of higher education student's ability to apply digital technologies to pursue common goals in collaborative settings and develop collaborative skills (European Commission, 2018; World Economic Forum, 2015).

Another educational implication is on an instrumental level. Applying this type of visualization might benefit the group members, as it can reveal how balanced higher education students' participation is. Knowing that a teacher easily can detect imbalances might also incentivize students to participate, as it becomes harder to hide behind other group members' efforts, and students with larger contributions might feel confident that their efforts will be noticed. On a conceptual level, the group could gain awareness of their stances toward knowledge and learning, and reflecting on whether those stances are productive or unproductive could greatly benefit them (e.g., Elby and Hammer, 2010; Limbu and Markauskaite, 2015).

In short, the results from this study suggests that developing higher education students' collaborative skills implicates higher educational settings with rich opportunities to practice. Combining OCW and visualization in teaching practices in such settings might be a fruitful strategy to develop students' collaborative skills.

\section{Ethical considerations}

The use of Google Docs in general, and teacher access to visualizations of student revision history in particular, raises the issue of ethical considerations in regard to DocuViz. It is inconsiderate to assume that 
students will or should accept to volunteer such information by default. Research on ethics in the context of learning analytics has pointed out the importance of addressing ethical issues for some time (e.g. Ferguson, 2012), but a minority of studies (18\% of 252 papers published 2012-2018) considers or even mentions ethical issues, although there seemed to be a rising trend in the last year (Viberg et al., 2018).

An issue in need of examination is that of surveillance, or dataveillance (Haythornthwaite, 2017), both in student-student interplay and in student-teacher interplay. At the core lies the transfer of private and personal information to third parties. This is only partly applicable to the particulars of the use of DataViz, but to a somewhat larger extent with the general case of Google. DataViz by itself does not process any other private data than the Google account name, and revision data is not aggregated or transferred to third parties. The remaining issue is the exposure of the revision history itself to the teacher. As pointed out by Kiliñska et al. (2019), there can be concerns that the teacher might interpret the data incorrectly due to lack of contextual knowledge on the way the group works. However, whether visualizations are used for formative purposes - or for summative assessment - could have an impact on students' attitudes towards the sharing of their revision history.

A potential positive implication of higher education students sharing revision history data with their teachers and each other that could outweigh some of the negative consequences are - according to some researchers - the benefits of meta-reflection on students' learning processes (Fontaine, 2002; Gerdes, 2010). But, without student acceptance for sharing, the positive implications would become degraded or nonexistent. The most crucial issue for achieving acceptance of such implementations of learning analytics systems is transparency on behalf of the teacher (Ifenthaler and Schumacher, 2016; Pardo and Siemens, 2014). It is therefore considered very important that the teacher clearly discloses information about "the collected data, its purpose, the underlying algorithms, the people who receive access to the data, and the analyses derived from them, as well as the amount of time the data will be stored and its degree of deidentification" (Ifenthaler and Schumacher, 2016, p. 934). Further work is needed in the formulation of a policy that can accommodate both the student's right to privacy and the potential benefits for formative assessment and learning process development.

\section{Further research}

An implication for research practices of the results of the current study is that the application of a visualization tool such as DocuViz might be a shortcut for scholars that aims at analyzing and understanding OCW practices. Such a shortcut might save time in the analytic process and provide opportunities for higher level of data analysis. Several further studies can be suggested from this implication. First, a larger sample of documents could be analyzed to test the validity of the suggested categories to see if they are generally applicable, and possibly determine generally applicable demarcating values for the suggested categories. Second, both higher education teachers' and students' perceptions of the use of DocuViz visualizations during OCW tasks could be evaluated. Do teachers perceive that it adds value to their teaching? Do students perceive the use of such a tool as beneficial for their epistemological awareness and/or the accountability of individual group members? Third, researchers could determine whether the use of DocuViz visualizations within OCW groups in higher education leads to better outcomes in terms of the quality of the produced documents through a quasi-experimental study. 


\section{References}

Al-Samarraie, H. and Saeed, N. (2018), "A systematic review of cloud computing tools for collaborative learning: Opportunities and challenges to the blended-learning environment", Computers E Education, Vol. 124, pp. 77-91.

Baker, M.J. (2015), "Collaboration in collaborative learning”, Interaction Studies: Social Behaviour and Communication in Biological and Artificial Systems, Vol. 16 No. 3, pp. 451-473.

Birnholtz, J., Steinhardt, S. and Pavese, A. (2013), "Write Here, Write Now!: An experimental study of group maintenance in collaborative writing", Proceedings of the SIGCHI Conference on Human Factors in Computing Systems, ACM, New York, NY, USA, pp. 961-970.

Di Lauro, F. and Johinke, R. (2017), "Employing Wikipedia for good not evil: Innovative approaches to collaborative writing assessment", Assessment E Evaluation in Higher Education, Vol. 42 No. 3, pp. $478-491$.

Dillenbourg, P. (1999), "What do you mean by 'collaborative learning'?”, in Dillenbourg, P. (Ed.), Collaborative Learning: Cognitive and Computational Approaches, Elsevier Science, Inc., New York, pp. $1-19$.

Elby, A. and Hammer, D. (2010), "Epistemological resources and framing: A cognitive framework for helping teachers interpret and respond to their students' epistemologies", in Bendixen, L.D. and Feucht, F.C. (Eds.), Personal Epistemology in the Classroom: Theory, Research, and Implications for Practice, Cambridge University Press, Cambridge, MA, pp. 409-434.

European Commission. (2018), Proposal for a Council Recommendation on Key Competences for Lifelong Learning, European Commission, Brussels.

Ferguson, R. (2012), "Learning analytics: drivers, developments and challenges", International Journal of Technology Enhanced Learning, Vol. 4 No. 5/6, p. 304.

Fischer, F., Bruhn, J., Gräsel, C. and Mandl, H. (2002), "Fostering collaborative knowledge construction with visualization tools", Learning and Instruction, Vol. 12 No. 2, pp. 213-232.

Fontaine, G. (2002), "Presence in 'Teleland”, in Rudestam, K.E. and Schoenholz-Read, J. (Eds.), Handbook of Online Learning: Innovations in Higher Education and Corporate Training, SAGE Publications, London ; Thousand Oaks, pp. 29-52.

Gerdes, A. (2010), "Revealing preconditions for trustful collaboration in CSCL", International Journal of Computer-Supported Collaborative Learning, Vol. 5 No. 3, pp. 345-353.

Haythornthwaite, C. (2017), "An information policy perspective on learning analytics", Proceedings of the Seventh International Learning Analytics \& Knowledge Conference, presented at the LAK '17: 7th International Learning Analytics and Knowledge Conference, ACM, Vancouver British Columbia Canada, pp. 253-256.

Ifenthaler, D. and Schumacher, C. (2016), "Student perceptions of privacy principles for learning analytics", Educational Technology Research and Development, Vol. 64 No. 5, pp. 923-938.

Jaldemark, J., Hrastinski, S., Olofsson, A.D. and Öberg, L.-M. (2018), "Editorial introduction: Collaborative learning enhanced by mobile technologies: Editorial", British Journal of Educational Technology, Vol. 49 No. 2, pp. 201-206.

Kilińska, D., Kobbelgaard, F.V. and Ryberg, T. (2019), "Learning Analytics Features for Improving Collaborative Writing Practices: Insights into the Students' Perspective”, in Väljataga, T. and Laanpere, M. (Eds.), Digital Turn in Schools—Research, Policy, Practice, Springer Singapore, Singapore, pp. $69-81$.

Larsen-Ledet, I. and Korsgaard, H. (2019), "Territorial Functioning in Collaborative Writing: Fragmented Exchanges and Common Outcomes", Computer Supported Cooperative Work (CSCW), Vol. 28 No. 3-4, pp. 391-433. 
Limbu, L. and Markauskaite, L. (2015), "How do learners experience joint writing: University students' conceptions of online collaborative writing tasks and environments", Computers E Education, Vol. 82, pp. 393-408.

Liu, M., Liu, L. and Liu, L. (2018), "Group awareness increases student engagement in online collaborative writing", The Internet and Higher Education, Vol. 38, pp. 1-8.

Liu, S.H.-J. and Lan, Y.-J. (2015), "Social constructivist approach to web-based EFL learning: Collaboration, motivation, and perception on the use of Google Docs", Educational Technology E Society, Vol. 19 No. 1, pp. 171-186.

Lowry, P.B., Curtis, A. and Lowry, M.R. (2004), "Building a taxonomy and nomenclature of collaborative writing to improve interdisciplinary research and practice", Journal of Business Communication, Vol. 41 No. 1, pp. 66-99.

McNely, B.J., Gestwicki, P., Hill, J.H., Parli-Horne, P. and Johnson, E. (2012), "Learning analytics for collaborative writing: a prototype and case study", Proceedings of the 2 nd International Conference on Learning Analytics and Knowledge - LAK '12, presented at the the 2nd International Conference, ACM Press, Vancouver, British Columbia, Canada, p. 222.

Olson, J.S., Wang, D., Olson, G.M. and Zhang, J. (2017), "How people write together now: Beginning the investigation with advanced undergraduates in a project course", ACM Transactions on ComputerHuman Interaction, Vol. 24 No. 1, pp. 4:1-4:40.

Onrubia, J. and Engel, A. (2009), "Strategies for collaborative writing and phases of knowledge construction in CSCL environments", Computers E Education, Vol. 53 No. 4, pp. 1256-1265.

Pardo, A. and Siemens, G. (2014), "Ethical and privacy principles for learning analytics: Ethical and privacy principles", British Journal of Educational Technology, Vol. 45 No. 3, pp. 438-450.

Paulus, T., Warren, A. and Lester, J.N. (2016), "Applying conversation analysis methods to online talk: A literature review", Discourse, Context \& Media, Vol. 12, pp. 1-10.

Posner, I.R. and Baecker, R.M. (1992), "How people write together (groupware)", Proceedings of the Twenty-Fifth Hawaii International Conference on System Sciences, Vol. IV, presented at the Proceedings of the Twenty-Fifth Hawaii International Conference on System Sciences, pp. 127-138 vol.4.

Ryberg, T., Davidsen, J. and Hodgson, V. (2018), "Understanding nomadic collaborative learning groups: Nomadic collaborative learning groups", British Journal of Educational Technology, Vol. 49 No. 2, pp. 235-247.

Sharples, M. (1993), "Adding a little structure to collaborative writing", in Diaper, D. and Sanger, C. (Eds.), CSCW in Practice: An Introduction and Case Studies, Springer, London, pp. 51-67.

Sharples, M., Goodlet, J.S., Beck, E.E., Wood, C.C., Easterbrook, S.M. and Plowman, L. (1993), "Research issues in the study of computer supported collaboraticve writing", in Sharples, M. (Ed.), Computer Supported Collaborative Writing, Springer, London, pp. 9-28.

Southavilay, V., Yacef, K., Reimann, P. and Calvo, R.A. (2013), "Analysis of collaborative writing processes using revision maps and probabilistic topic models", Proceedings of the Third International Conference on Learning Analytics and Knowledge - LAK '13, presented at the the Third International Conference, ACM Press, Leuven, Belgium, pp. 38-47.

Stratton, C.R. (1989), "Collaborative writing in the workplace", IEEE Transactions on Professional Communication, Vol. 32 No. 3, pp. 178-182.

Sun, Z., Lin, C.-H., Wu, M., Zhou, J. and Luo, L. (2018), "A tale of two communication tools: Discussion-forum and mobile instant-messaging apps in collaborative learning", British Journal of Educational Technology, Vol. 49 No. 2, pp. 248-261.

Tan, S. and Tan, A. (2006), "Conversational analysis as an analytical tool for face-to-face and online conversations", Educational Media International, Vol. 43 No. 4, pp. 347-361. 
Viberg, O., Hatakka, M., Bälter, O. and Mavroudi, A. (2018), "The current landscape of learning analytics in higher education", Computers in Human Behavior, Vol. 89, pp. 98-110.

Wang, D., Olson, J.S., Zhang, J., Nguyen, T. and Olson, G.M. (2015), “DocuViz: Visualizing collaborative writing", Proceedings of the 33rd Annual ACM Conference on Human Factors in Computing Systems - CHI '15, presented at the 33rd Annual ACM Conference, ACM Press, Seoul, Republic of Korea, pp. $1865-1874$.

World Economic Forum. (2015), New Vision for Education: Unlocking the Potential of Technology, World Economic Forum, Geneva, Switzerland.

Zhang, X., Meng, Y., Ordóñez de Pablos, P. and Sun, Y. (2019), "Learning analytics in collaborative learning supported by Slack: From the perspective of engagement", Computers in Human Behavior, Vol. 92, pp. 625-633. 